\title{
New Frontiers in Healthcare and Technology: Internet-and Web-Based Mental Options Emerge to Complement In-Person and Telepsychiatric Care Options
}

Don Hilty*, Steven Chan, John Torous, Jesse Mahautmr and Davor Mucic

Chief of Consultation-Liaison Psychiatry, LAC+USC Medical Center, Keck School of Medicine, USA

\begin{abstract}
Background: Web and Internet-based resources are remarkably popular with the public, patients and others as a way to access mental health information, tools for self-care, advice/consultation from a professional, and providerdirected treatments.

Objective: This paper provides a framework of a spectrum that includes person-centered health education options (conceptual endpoint), patient and caregiver-centered mental health care interventions (evidence-based literature review), and more formal provider-directed treatments (conceptual endpoint).

Methods: The evidence-based literature review was focused on treatment studies, using a minimum of three key words and the 1996-2015 period, resulting in 13,612 articles. This was reduced to 388 (title words used), to 125 (abstracts for methods, design, and outcomes) and 40 (evidence-based criteria of guidelines).

Results: Technology is frequently used, is readily accessible and satisfies persons, patients, and caregivers. Its impact on openness to engage with others and begin self-care appears very positive; its ability to help people change behaviors and engage additional clinical services appears modest, though this is inadequately evaluated. Formal treatments over the Internet, asynchronous care models, or traditional video-based synchronous services are as good as or better than in-person services, though an incomplete range of services has been evaluated. Relatively few treatment studies assess outcomes, compare in-person and e-MentalHealth care, and or compare technology-based care options to one another; hybrid models of care have emerged, but have rarely been studied.

Conclusions: For persons or patients not in care, use of the internet for common, non-acute problems appears to work, though a one-time clinical evaluation may help them place options in context. Clinicians and patients should specifically plan how to use technology and exercise sound judgment, based on guidelines when available. More research is needed on the application of new technologies to clinical care, with randomized trials and health services studies for effectiveness suggested.
\end{abstract}

Keywords: Primary words were apps; Care; Caregiver; Centered; Education; Effectiveness; Efficacy; Emotional; Internet; Mental; Mobile; Outcome; Patient; Person; Practice; Quality; Reliability; Research; Satisfaction; Service; Technology; Validity; Web-based

Secondary keywords: Aynchronous; Hybrid; E-mental; Health; Face-to-face; In-person; Synchronous; Telemedicine; Telemental; Telepsychiatry; Videoconferencing

\section{Introduction}

Globally, Africa, the Middle East, and Latin America are the fastest growing populations in terms of Internet usage; in the United States, Internet use has grown dramatically over the past decade, with a jump from $44 \%$ of the population $[1,2]$. Online health information varies in quality and readability [3-5], but it has helped users feel empowered, be more confident (i.e., self-efficacy), suffer less anxiety, make decisions on health-related behaviors, and feel more connected to their doctor [6-9]. The Internet overcomes geographic distance, serves those with special needs (i.e., autism-spectrum, sensory and motor disabilities), reduce the impact of immobility (i.e., panic disorder or phobias) and suits generational preferences (i.e., teenagers). Social networking has been defined as web-based services that allow individuals to (1) construct a public or semi-public profile within a bounded system, (2) share a connection with specific users, and (3) view and traverse their list of connections and those made by others within the system [10]. A meta-analysis shows that health behaviors change with this medium [11].

A review of 115 studies on e-mental health (eMH) from 2005 to
2010 reported that $94 \%$ were peer-reviewed and 51\% were described as primarily research $[12,13]$. Most of the research $(76 \%)$ originated in the United States, Australia, or the Netherlands. Four areas of e-MH service delivery were identified: information provision; screening, assessment, and monitoring; intervention; and social support. E-MH has been defined as "mental health services and information delivered or enhanced through the Internet and related technologies" [14]. However, there is no agreement on a field-specific definition. Some scholars consider e-MH to include only initiatives delivered directly to $\mathrm{MH}$ service users [15] and only on the Internet [15,16], as opposed to, for example, delivery via stand-alone computers or video seminars. The terms telemental health (TMH) and telepsychiatry have typically been used for traditional MH care services provided synchronously by videoconferencing [17], or asynchronously (e.g., provider interview of a patient, with video capture, uploading additional information, and

*Corresponding author: Don Hilty, Professor and Vice Chair of Education, Chief of Consultation-Liaison Psychiatry, LAC+USC Medical Center, Keck School of Medicine, USA, Tel: 323442 4000; E-mail: hilty@usc.edu

Received June 30, 2015; Accepted August 13, 2015; Published August 20, 2015

Citation: Hilty D, Chan S, Torous J, Mahautmr J, Mucic D (2015) New Frontiers in Healthcare and Technology: Internet-and Web-Based Mental Options Emerge to Complement In-Person and Telepsychiatric Care Options. J Health Med Informat 6 200. doi:10.4172/2157-7420.1000200

Copyright: (c) 2015 Hilty D, et al. This is an open-access article distributed under the terms of the Creative Commons Attribution License, which permits unrestricted use, distribution, and reproduction in any medium, provided the original author and source are credited. 
Citation: Hilty D, Chan S, Torous J, Mahautmr J, Mucic D (2015) New Frontiers in Healthcare and Technology: Internet-and Web-Based Mental Options Emerge to Complement In-Person and Telepsychiatric Care Options. J Health Med Informat 6: 200. doi:10.4172/2157-7420.1000200

Page 2 of 14

transmission in a Health Insurance Portability and Accountability Act (HIPAA)-adherent manner to a remote psychiatrist) [18].

Internet-based mental health $(\mathrm{MH})$ education and services are on the rise, as more patients, caregivers, and $\mathrm{MH}$ providers are using the Internet. This is driven by consumers or persons at-large, before they become patients in traditional services, and transitions our thinking from clinic-based care past patient-centered care to person-centered care known as participatory medicine [19-21]. MH-related, technology-based services exist on a continuum: self-help/support groups - well-prepared materials for patient psychoeducation and provider professional education - tips for assessment and selfcare (e.g., depression) - informal provider consultation online - asynchronous communication with providers - MH services with professionals like teleMH ((TMH) care or; Internet-based cognitive behavioral treatment (CBT) [22-30].

Consumers, patients, caregivers and providers use a variety of sources of information, turn to it for many reasons, and use the information for next step planning (Table 1). A population survey assessed Internet use, past psychiatric history and the 12item General Health Questionnaire [31]. It showed that $18 \%$ of all Internet users had used it for MH information, with the prevalence higher among those with a past history of $\mathrm{MH}$ problems and those with current psychological distress. Second, the quality of the information varies. Only $12 \%$ selected the Internet as one of the three most accurate sources of information, but $24 \%$ said it was one of the three sources they would use. A survey of $600+$ students of law, nursing and computer science in Spain, using a 25 -item questionnaire, found they had a strong distrust in online $\mathrm{MH}$ information, notwithstanding their daily use of the Internet [32]. The frequency and methods of their research on the Internet correlated with their health status and their frequency of medical appointments.

MH providers face many challenges with these emerging technologies, and they, like many others in society, may fear the trends [33]. First, how do they keep up with the slew of new options patients are using, particularly adult clinicians not pulled along by child and adolescent patients? Second, how do they evaluate the technologies or help patients do so? This is particularly true for psych apps for smartphones [34]. Third, can we assume the person or patient will use the "right" service at the "right" time (e.g., not using social media when expressing suicidal ideation)? More broadly, though, do the advantages (empowerment, in-time learning, increased self-efficacy) outweigh the liabilities? Finally, when patients are starting care - or already in care - what steps do patients and clinicians need to take to track and evaluate use (e.g., do clinicians and programs change treatment plans and expectations for outcomes? If a patient follows inaccurate advice, he/she may have a bad outcome or may have longer suffering due to delayed access of the "right" or better care option). Assuming that patients will inform and discuss the options with clinicians may be too optimistic.

The American Telemedicine Association Practice Guidelines for TMH Care [35] and Video-Based Online Mental Health Services do not cover all the new nooks and crannies of the technology innovations [36]. The former focuses on synchronous standards and the latter on initiation and reception of services using personal computer with a webcam or a mobile communications device (e.g., "smart phone", laptop, or tablet; with two-way camera capability. Neither guideline addresses communications between professionals and consumers or patients via texting, e-mail, chatting, social network sites, online "coaching" or other non-MH services. Many persons or patients are using self-help services to complement regular care (i.e., hybrid models) [37].

This paper will...

1) Review the literature on patient and caregiver sought $\mathrm{MH}$ information, self- or patient-directed assessment, informal treatment options, and semiformal treatment options,

2) Propose a spectrum of $\mathrm{MH}$ information to clinical care options; it places the above evidence-based review about treatment between an endpoint with informal Internet-based $\mathrm{MH}$ education and another endpoint of formal clinical care/treatment options coowned by patients and clinicians.

3) Help the clinician to gain a relative sense of the similarities, differences, and complimentary fit of new technology-based options, in-person care, and video-based traditional care models,

4) Provide an overview of the formal guidelines for traditional e-MH care, informal guidelines for new technology-based care options, and suggest preliminary considerations on how to approach innovative patient-centered/driven care options.

\section{Methods}

The review of the literature was conducted in the MEDLINE, PubMed, psycINFo, EMBASE, Science Citation Index, Social Sciences Citation Index, Telemedicine Information Exchange databases, Centre for Reviews and Dissemination, and The Cochrane Library Controlled Trial Registry databases for the period of July 1996 to March 2015. Primary words were apps, care, caregiver, centered, education, effectiveness, efficacy, emotional, Internet, mental, mobile, outcome, patient, person, practice, quality, reliability, research, satisfaction, service, technology, validity, web-based. Secondary words were asynchronous hybrid, e-mental, health, face-to-face, in-person, synchronous, telemedicine, telemental, telepsychiatry, and videoconferencing. The evidence-based literature review was focused on treatment studies, using a minimum of three key words and the 1996-2015 period, resulting in 13,612 articles. This was reduced to 388 (title words used), to 125 (abstracts for methods, design, and outcomes) and 40 (evidence-based criteria of guidelines) (Levels I and II). For the endpoints (health information; formal treatment studies), recent references indicative of typical programs/resources were used to supplement the framework, including the end with e-MH, telehealth, telepsychiatry, and hybrid MH care.

The standard for guidelines for evidence bases is set by the Institute of Medicine and partnering medical organizations, with reviews by the Agency for Healthcare Quality and Research (AHQR) and Cochrane Database of Systematic Reviews [38-41]. A fundamental feature is a panel of multidisciplinary experts to rate two factors: 1) the quality of evidence (e.g., Levels I (best) to IV (least)); and 2) consensus, expert opinion. Level I includes: a high quality randomized controlled trial (RCT) or prospective study; testing of previously developed diagnostic criteria on consecutive patients; sensible costs and alternatives; values obtained from many studies with multi-way sensitivity analyses; and systematic review of such Level I studies. Level II includes: a lesser quality RCT; prospective comparative study; retrospective study; untreated controls from an RCT; lesser quality prospective study; development of diagnostic criteria on consecutive patients; sensible costs and 
Citation: Hilty D, Chan S, Torous J, Mahautmr J, Mucic D (2015) New Frontiers in Healthcare and Technology: Internet-and Web-Based Mental Options Emerge to Complement In-Person and Telepsychiatric Care Options. J Health Med Informat 6: 200. doi:10.4172/2157-7420.1000200

Page 3 of 14

alternatives; values obtained from limited studies; with multi-way sensitivity analyses; and a systematic review of Level II studies or Level I studies with inconsistent results.

\section{Web- and Internet-based patient-centered/driven self-help, informal peer education, resources for caregivers, and self- assessment and care inroads}

Health information: who seeks it and what do they want?: The users of the Internet are mostly female ( $86 \%$ vs. $73 \%$ of men) and seek information on diseases or medical problems, treatments or procedures, doctors or other health professionals, hospitals or other medical facilities, food safety or recalls, drug safety or recalls, and pregnancy and childbirth [1,2]. Caregivers (a term used for adults who provide unpaid care to a parent, child, friend or other loved ones) usually have access to the Internet (79\%) and of those, $88 \%$ look online for health information. One's education affects use $(89 \%$ of those with a college degree vs. $70 \%$ with a high school degree vs. $38 \%$ without a high school diploma. Income is a predictor, as well (95\% with household income $\$ 75,000+$ and $57 \%$ with $<\$ 30,000)$.

A systematic review of the effectiveness of online services in facilitating MH help-seeking in young people aged 14-25, emphasizing rigorous designs $(\mathrm{N}=18)$ showed high satisfaction and higher use by females [42]. There was no change in help-seeking behavior in $(\mathrm{N}=3)$ RCTs, but a quasi-experimental study showed a slight but significant increase in help-seeking [42]. The cross-sectional studies reported that online services facilitated seeking help from a professional source for $35 \%$ of users. Limitations included small sample sizes and inadequate measurement of help-seeking.

Many patients migrate to sites like Patients Like Me (http:// www.patientslikeme.com/), a consumer driven site where individuals connect with others in the community who are experiencing similar medical issues. Young people with developmental challenges may have few traditional care options and feel more comfortable anonymously or at a distance, to share experiences and try to learn new behaviors [43]. Comfortable with Internet-based chats and groups, they may even express ideas of self-harm, negative affective states, or pessimistic cognitions of other peers $[44,45]$. This is concerning, though, if these things are not shared with parents and/or professionals. Anxiety (phobias or panic disorder) or trauma (e.g., military personnel with PTSD) patients may be avoided [46].

Common prejudice is that psychotic patients are not eligible for remote consultations and that they do not use of technology, in general. This is attributed to stimulus overflow and inability to deal with the abundance of information, difficulties with concentration during psychosis, lack of energy, paranoid ideas and fear of symptom provocation. However, they successfully use the Internet for information related to their illness and medication (e.g., side effects and the hope of finding better medication) [47-49]. On the other hand, patients may feel the need to guard themselves against excess information that Internet frequently offers. For loved ones of these patients, the simulated reality game "Second Life" described below, when used as an educational tool, may improve the user's understanding of psychotic symptoms (i.e., auditory- and/or visual hallucinations [50]. Health promotion strategies are typically at freestanding websites [51].

A community sample of young adults assessed the impact of patient-related factors, for e-MH care and the impact on use of conventional services for $\mathrm{MH}$ care in France [52]. Factors were organized into: 1) predisposing factors (age, sex, educational attainment, professional activity, living with a partner, children, childhood negative events, chronic somatic disease, parental history of depression); 2) enabling factors (social support, financial difficulties, parents' income); and 3) needs-related factors (lifetime major depression or anxiety disorders, suicidal ideation, ADHD, cannabis use). Overall, 8.65\% (105/1214) of participants reported seeking e-MH care in case of psychological difficulties in the preceding 12 months and $15.7 \%$ reported psychological difficulties. The likelihood of e-MH care was positively associated with lifetime major depression/anxiety disorder and lifetime suicidal ideation; the predisposing factor of childhood life events was negatively correlated. E-MH care did not hinder traditional care, but was associated with face-to-face psychotherapy.

Support groups and participation in a "community.": Most support groups are for consumers and patients, based on the following premises: 1) knowledge affects changes in behaviors, 2) peer support/feedback help with changes (or in some cases, the opposite), and 3) even informal contact by e-mail, chat or telephone with a health care provider feels personalized and affects such changes. Internet-mediated support groups can include specialized groups for individuals with disabilities or unique modes of experience [53].

Web-based support has coalesced in MH around certain groups of users (e.g., caregiver) and specific populations. These include:

- Individuals with stigmatizing or rare illness with social isolation [54].

- Schizotypal personality disorder patients, who have interest in social interaction on the Web [55] and interpersonal relationships without the usual in-person difficulties.

- Military personnel re-entry into regular life [56], whose fear of stigma reduces help-seeking $[57,58]$ and who prefer technologybased platforms (e.g., 33\% of personnel were more willing to use a technology-based platform for $\mathrm{MH}$ care than talk to a counselor in-person) [59].

- In about $2 / 3$ of studies, caregivers who use Internet-based services have significantly reduced stress and improved quality of life for MH disorders [12]. They use interactive communities to bulletin board therapy groups. Family caregivers located in rural areas found e-health support to be beneficial in comparison with conventional caregiver support [60].

Formal materials or opportunities for consumers, patients, caregivers and providers: Some consumers, patients, caregivers (psychoeducation) and providers (professional education) are seeking robust, structured programs like bulletin boards, videos, and advocacy sites. Many Internet-based materials and opportunities to learn exist for caregivers of patients, for those with MH (dementia, schizophrenia, anorexia) and medical disorders [12]. Services included webcasts, discussion boards, online classes, learning modules, and chat rooms; the best outcomes were best for satisfaction and comfort with services via cell phones [61]. Continuing medical education resources [62] are increasingly available.

Young people may benefit from structured health information, webbased screening and assessment, and online treatment options-across many settings-as free-standing promotion sites, programs at school, and combination home/primary care settings or home/MH specialist settings. Many Internet interventions have been developed to provide broad MH promotion in children and adolescents: Kindertelefoon 
Citation: Hilty D, Chan S, Torous J, Mahautmr J, Mucic D (2015) New Frontiers in Healthcare and Technology: Internet-and Web-Based Mental Options Emerge to Complement In-Person and Telepsychiatric Care Options. J Health Med Informat 6: 200. doi:10.4172/2157-7420.1000200

Page 4 of 14

(www.kindertelefoon.nl), YooMagazine (www.Yoomagazine.net), Ciao, ReachOut (www.reach-out.org) and Walkalong (www.walkalong. ca) particularly target youth.

Psych apps and other tools for self-directed habit, lifestyle or illness changes: These tools typically target good habits/health promotion, disease prevention, and informal management of symptoms or problems. Techniques might include use of a diary, a questionnaire or survey to provoke reflection or "stepping back" to re-evaluate one's assumptions in a conclusion. Exercise and substance (i.e., alcohol) logs are popular, mood assessments (MoodyMe https://itunes.apple. com/us/app/moody-me-mood-diary-tracker/id411567371? $\mathrm{mt}=8$ ), and those that map behavior patterns across time, including triggers, diet, sleep and other related factors. Stress reduction programs using a mobile phone app is an increasing field of interest because of a large number of potential users and economical impacts on community [63].

Precision Medicine [64] suggests the drive towards more individualized medicine may be less based on epidemiological and consensus-driven algorithms, and more by informatics, laboratory medicine, and testing. Uptake of apps has generally been slow in $\mathrm{MH}$, as $\mathrm{MH}$ organizations were not eligible to receive federal start-up funding for IT infrastructure. Mobile apps offer 1) portability for access anytime, anywhere, regardless of patient geography and transportation barriers; 2) an inexpensive option versus traditional desktop computers; and 3) additional features (e.g., context-aware interventions and sensors [65] with real-time feedback. MH app demand is high across censusdesignated areas, generations, and, to a degree, age, with less use by older adults [65]. Text messaging may be higher in urban areas [66] than rural areas [67].

Psych apps are used mainly for many functions, including to: 1) communicate with other patients, caregivers, social supports, or providers; 2) augment psychotherapy and medical support with journaling, diaries, symptom tracking tools, and psychoeducation between clinic appointments; 3) (smart) monitor, that is, to use tools to predict relapse behavior or worsening affective symptoms, through sensors and data activity; 4) practice self-assessment and care through reflection about their symptoms; 5) make learning more interactive than traditional paper homework; and 6) organize, track, and thus monitor long-term their activities, moods, and therapy homework $[22,68,69]$. Since patients often forget key events between visits, logging "symptoms, affect, behavior, and cognitions close in time to experience" (known as ecological momentary assessment; EMA) helps with reporting of symptoms $[70,71]$

Various mobile apps especially those focusing on self-help in dealing with anxiety disorders, $\mathrm{MH}$ well-being and stress reduction, have been adjusted so that various patient groups may benefit from them. One example is "Fear Fighter", a computer guided self-exposure approach to treat phobia/panic developed at the end of last century [72]. Exposure therapy is effective for phobia/panic but qualified and trained therapist resources are scarce. A computer-guided approach can make most of the treatment suggestions, and still achieve formidable results; both patients and clinicians achieve benefits by saving time and enhance health care efficiency [73].

App designers are not always clinicians, but if they were, there may be better accuracy of the content [74] and it may be more straightforward for trainees to use them [75]. Recent studies suggest that clinicians should be involved in the development process and a simple methodology of creating an app has been proposed, using just an Internet browser and a text editor [76]. The barriers are typical: anxiety/ fear, technical skills (e.g., coding in computer programming language) and time. In psychiatry, the latest app advance is for resident training in psychodynamic therapy [77]. A search revealed 166 and 240 psychiatry apps on the Apple's ios-based App Store and the Android Google Play Store, respectively, but a scarcity of high-quality, comprehensive, textbook grade e-learning materials [78]. A survey of medical students ( $\mathrm{N}=185$; mean age 22; users of Apple IOS devices) showed that $66.7 \%$ had between 1-5 medical smartphone apps, used mainly for classroom and clinic purposes; $95.2 \%$ of the students indicated that having a psychiatry smartphone application would be useful, preferably with textbook content and clinical videos embedded [78].

\section{Clinician-assisted decisions, telepsychiatric care and other evidence-based options}

Informal advice from health professionals without guidance: Some of the above options, while not considered "care," involve some oversight by $\mathrm{MH}$ providers (e.g., depression). This usually involves bulletin boards with occasional comments or steering by professionals. For example, in an asynchronous chat group with education, the provider can participate periodically (e.g., paper, video or other) based on the discussion to provide information, corrections of misunderstood concepts or distortions, or review of self-report measures with a followup piece of advice. Ironically, sometimes the "best" outcome of one of these forums is when a patient is referred to see a professional when things are not simple or there is a perception by the facilitator that too many concurrent problems are at-hand.

In a recent study, researchers reviewed the public social networking accounts of college students to assess for symptoms of depression, finding that $25 \%$ exhibited depressive symptoms based upon the Diagnostic and Statistical Manual of Mental Disorders (DSM-IV-TR) [79] criteria, and $2.5 \%$ met the criteria for major depressive disorder. Online reinforcement from their friends may have made them more likely to discuss their depressive symptoms publicly via social networking sites [80].

Support and self-help programs are delivered via Internet especially to rural areas but also within urban environments - for patients and caregivers. These allow anonymous questions, offer relevant treatment ideas, and self-help interventions without stigma (e.g., severe mentally ill or individuals with drinking problem) [81]. The range of initiatives for support for caregivers includes hotlines for consultation on key decisions (i.e., decision support), psychosocial/CBT (individual or group), problem solving training, coaching for positive parenting skills (e.g., Internet- or app-based follow-up assessment and engagement of treatment), and use of formal questionnaires to self-diagnose and refer loved ones (e.g., Patient Health Questionnaire for depression; hospital anxiety and depression scale).

Innovations or additions to regular traditional treatments: The least structured of these options is patient-doctor correspondence integrated with clinical care and the EHR. As the Internet increases level of knowledge and information amount regarding specific illness, the users may more easily talk to their doctor regarding their specific conditions and potential treatment options [9]. Schizophrenic patients especially perceive the shift in hierarchy to a more equal relationship. In this respect, a specific advantage for patients with psychosis is not having to face another person, but still being able to gain information and interact with others without feeling devalued or unsafe [47].

Psych apps, as described above, are used for many reasons in supplementing or complementing care, including to: 1) augment psychotherapy and medical support with journaling, diaries, symptom tracking tools, and psychoeducation between traditional face-to-face 
Citation: Hilty D, Chan S, Torous J, Mahautmr J, Mucic D (2015) New Frontiers in Healthcare and Technology: Internet-and Web-Based Mental Options Emerge to Complement In-Person and Telepsychiatric Care Options. J Health Med Informat 6: 200. doi:10.4172/2157-7420.1000200

Page 5 of 14

clinic appointments; 2) encourage self-assessment and reflection about their symptoms; and 3) make learning more interactive than traditional paper homework $[22,68,69]$. Apps are beginning to be used for illness-specific education, treatment resource location, and tracking of treatment progress [82]. Psychometric measures such as the Patient Health Questionnaire (PHQ-9) [83] and other military population measures are preferred by soldiers by iPhone rather than paper or computer due to its interface, portability, and convenience [84]. An app called PTSD Coach (http://www.ptsd.va.gov/public/ pages/PTSDCoach.asp) has been designed to help veterans learn about and manage symptoms that commonly occur after trauma [85]. It also has direct links to support and help; such apps are not designed to act as a substitute for treatment.

One promising area is supporting patients in attendance to treatment, which is a common reason psychiatric treatments fail to produce intended outcomes. Unfortunately, only about half of all patients obtain psychiatric treatment [86] due to stigma and poor insight. Direct or remote education, motivation and support may increase attendance (i.e., treatment readiness), recognition of treatment benefits, and collaboration between care providers - all contribute to a positive psychiatric treatment [87]. Recent patient-centered strategies that increase patient attendance and adherence to treatment include simple mail, telephone or SMS reminders $[88,89]$.

Internet-based CBT (ICBT) and other evidence-based treatments are most often for patients with depression and anxiety. ICBT appears to be effective when delivered in clinical practice (i.e., guided by a qualified therapist $[90,91]$. Effect size and recovery rates were comparable to, or somewhat superior to, in-person CBT [92]. Internetbased cognitive therapy (CT) is often combined with text messages (mobile cognitive therapy; $\mathrm{mCT}$ ) and therapist e-mail and telephone contact - this prevents relapse in depression, is acceptable and is feasible for both patients and therapists [93]. Online MH interventions are also as effective as traditional in-person therapy for disorders such as depression and anxiety [94-97]. In a 30-month study using CBT for social phobia research, the long-term effects of in-person delivered CBT was comparable to Internet-based treatment [97].

Asynchronous telepsychiatry (ATP): ATP to primary care is feasible, valid and reliable in English and Spanish-speaking patients in primary care [18]. Similar methods are used in radiology, dermatology, ophthalmology, cardiology and pathology. One ATP model uses a basic questionnaire for screening by the provider of the patient, video capture of that interview, and uploading of patient histories for a remote psychiatrist for review in a HIPAA-adherent manner [18]. Diagnosis and treatment recommendations are made and PCPs implement care successfully about $80 \%$ of the time and the model is cost-effective $[98,99]$.

Synchronous TP (STP) or TMH: E-MH models of clinical care and education have pros and cons $[17,100,101]$, including their level of overall intensity, cost, feasibility and depth of the relationship between the TmH provider, the PCP and patient. Low intensity models include tele-education, formal case review and in-person, telephone or email doctor-to-doctor "curbside" consultations. A systematic approach was a multi-specialty phone and email teleconsultation system for adults and children with developmental disabilities [102]. Moderate intensity models include an integrated program of $\mathrm{MH}$ screening, therapy on site, and telepsychiatric consultation (phone, email or video), with continuing medical education (CME) and training on screening questionnaires $[103,104]$ or asynchronous telepsychiatry (ATP) to primary care in English and Spanish-speaking patients in primary care $[18,98,99]$. High intensity models are typically the ones previously mentioned involving collaborative care [105-107].

Improved access at a distance to rarely available standard treatments: Rapid eye movements are part of the Eye Movement Desensitization and Reprocessing approach typically used for treatment of a patients suffering from an acute stress disorder. However, experts who provide uncommon treatments may be difficult to find in one's community, which is why a videoconference mediated treatment has been tested with promising results [108].

TMH has contributed to development of "remote speech therapy," a Swedish innovation since 2010. This has been well established in rural areas of Sweden, Finland and Scotland [109]. The aim of the project was to reduce therapists' travel time while enabling patients in rural communities to have better access to speech and language therapy services. School children living in remote communities had the opportunity to receive therapy sessions in their schools while the speech therapist was located at a central location.

New treatments with a growing evidence base (e.g., virtual reality (VR): VR is usually defined as "a computer-simulated environment that can simulate physical presence in places in the real world or imagined worlds." VR can recreate sensory experiences, which include virtual taste, sight, smell, sound, and touch. There are VR platforms for games, entertainment, marketing, flight simulation, medical education and other fields, and now the virtual characters (avatar, virtual agent) and environments are being used to practice dynamic and real-life social interactions in a safe environment $[30,110]$. The virtual character (avatar) may be a graphical representation of the user or the user's alter ego in 3D form; people are known to psychologically identify with virtual representations that do not necessarily reflect their actual appearances [111]. Moreover, the appearance of avatars can cause behavioral and attitudinal shifts that might positively influence current treatment or motivate individuals who were reluctant to that due to lack of insight or stigma [30].

Virtual environments used in these approaches are either singleuser virtual environments (SVEs) or collaborative virtual environments (CVEs). In an SVE, a single user explores the virtual environment and responses from the environment or a virtual agent (avatar) must be preprogrammed. CVEs have been used to examine and investigate the ability to recognize emotions [112], and also teach students how to manifest their emotions and understand the emotions of other people [113]. A prototype Internet-based VR apps was Second Life (http:// secondlife.com/) [114]. Virtual characters and environments represent a valuable tool for the supportive therapies and the training of social skills and non-verbal decoding (e.g., high-functioning autism), as they provide a safe, repeatable and diversifiable learning environment [115] There are few problems, though as when participating in violent games, avatars personalize risk by simulating harm to digital representations with which people directly identify, and this may be upsetting [116]

Another type of a VR platform is a fully immersive system. These fully immersive software systems give the user a full immersion in the virtual reality environment. A review of VR reports it has been used in the treatment of many psychological issues [114], including eating disorders, autism spectrum disorders, stress management, pain management, and PTSD (e.g., VR exposure therapy (VRET), used in the treatment of phobia and trauma-related disorders like PTSD). One avatar therapy program has helped schizophrenic patients significantly reduce the frequency and intensity of the voices, their omnipotence and malevolence [117]. The treatment involves having a schizophrenic 
Citation: Hilty D, Chan S, Torous J, Mahautmr J, Mucic D (2015) New Frontiers in Healthcare and Technology: Internet-and Web-Based Mental Options Emerge to Complement In-Person and Telepsychiatric Care Options. J Health Med Informat 6: 200. doi:10.4172/2157-7420.1000200

Page 6 of 14

\begin{tabular}{|c|c|c|c|c|c|}
\hline Level & Source/Entry & Initiator Goals/Aims & Questions And Perspectives & Liabilities & Other Comments \\
\hline 1 & $\begin{array}{l}\text { Website information } \\
\text { and support/chat } \\
\text { groups }\end{array}$ & $\begin{array}{l}\text { Health information: gain perspective, } \\
\text { obtain standard and updated info } \\
\text { Answers, tips and perspective }\end{array}$ & $\begin{array}{l}\text { How should I approach the } \\
\text { problem? } \\
\text { What should I do or what are others } \\
\text { doing? }\end{array}$ & $\begin{array}{l}\text { Quality of information and } \\
\text { lack of regulation }\end{array}$ & $\begin{array}{l}\text { Better if referred by clinician } \\
\text { who has evaluated the } \\
\text { materials }\end{array}$ \\
\hline 2 & $\begin{array}{l}\text { Formal educational } \\
\text { materials }\end{array}$ & $\begin{array}{l}\text { Person/patient: education } \\
\text { Caregiver: education, supports, and } \\
\text { advice } \\
\text { Clinician: continuing medical } \\
\text { education }\end{array}$ & $\begin{array}{l}\text { An effort to improve or to show effort } \\
\text { (if referred by other)? } \\
\text { Using evidence-based or "sound" } \\
\text { info } \\
\text { Documenting progress }\end{array}$ & $\begin{array}{l}\text { Less interaction with } \\
\text { instructors or clinicians } \\
\text { May present a learning style } \\
\text { mismatch }\end{array}$ & $\begin{array}{l}\text { Better if referred by clinician } \\
\text { who has evaluated the } \\
\text { materials }\end{array}$ \\
\hline 3 & $\begin{array}{l}\text { Self-directed } \\
\text { assessment and care }\end{array}$ & $\begin{array}{l}\text { Person/patient: good habits, } \\
\text { reflection tips } \\
\text { Caregiver: reflection tips, tools to } \\
\text { assess loved ones } \\
\text { Clinician: tips on clinical care, } \\
\text { options to refer patients }\end{array}$ & $\begin{array}{l}\text { If it is my preference/style (or I } \\
\text { have limited resources), what can I } \\
\text { accomplish? } \\
\text { Is this problem serious? } \\
\text { Can my patients do some of this } \\
\text { outside the office? }\end{array}$ & $\begin{array}{l}\text { Not all problems can be self- } \\
\text { assessed } \\
\text { Some illnesses affect our } \\
\text { insight } \\
\text { Is it "really good," though? }\end{array}$ & $\begin{array}{l}\text { Better if referred by clinician } \\
\text { who has evaluated the } \\
\text { materials }\end{array}$ \\
\hline 4 & $\begin{array}{l}\text { Assisted self-care } \\
\text { assessment, traditional } \\
\text { evaluation and } \\
\text { decision-making, and } \\
\text { automated support } \\
\text { systems }\end{array}$ & $\begin{array}{l}\text { Person/patient/caregiver: } \\
\text { empowering } \\
\text { Clinician: skepticism unless the } \\
\text { resource is of known quality and } \\
\text { reputation }\end{array}$ & $\begin{array}{l}\text { Empowering and increased self- } \\
\text { efficacy/confidence in next step? } \\
\text { Could this address MH provider } \\
\text { shortage and costs? }\end{array}$ & $\begin{array}{l}\text { Risk of oversimplification } \\
\text { and misdiagnosis in } \\
\text { receiving an opinion without } \\
\text { them knowing you }\end{array}$ & $\begin{array}{l}\text { Alternative might } \\
\text { be members of an } \\
\text { interdisciplinary team or } \\
\text { lower-cost providers }\end{array}$ \\
\hline 5 & $\begin{array}{l}\text { Asynchronous, } \\
\text { between-session } \\
\text { clinician contact }\end{array}$ & $\begin{array}{l}\text { Person/patient/caregiver: contact, } \\
\text { advice } \\
\text { Clinician: don't make quick } \\
\text { decisions, not that simple, and } \\
\text { preference to schedule/bill }\end{array}$ & $\begin{array}{l}\text { Builds relationship and clinician is } \\
\text { "available" }\end{array}$ & $\begin{array}{l}\text { Patient-clinician may have } \\
\text { different styles; things } \\
\text { taken out of context; and } \\
\text { miscommunication } \\
\text { Needs new models of } \\
\text { clinical support }\end{array}$ & $\begin{array}{l}\text { Will most likely increase } \\
\text { over time }\end{array}$ \\
\hline 6 & $\begin{array}{l}\text { Synchronous, } \\
\text { traditional or e-MH care }\end{array}$ & $\begin{array}{l}\text { Person/patient: gold standard of care } \\
\text { with more research } \\
\text { Clinician: if patients like it, it is a } \\
\text { good option }\end{array}$ & $\begin{array}{l}\text { There is no shortcut to synchronous } \\
\text { decision-making (patient-clinician; } \\
\text { primary care-psychiatry) }\end{array}$ & $\begin{array}{l}\text { It always has to be } \\
\text { scheduled (and paid for) }\end{array}$ & $\begin{array}{l}\text { A great option; not always } \\
\text { needed due to lesser, easier } \\
\text { options }\end{array}$ \\
\hline
\end{tabular}

Table 1: The Continuum of Internet-Based Options For Informal Mental Health (MH) Education, Self-Directed Care and Traditional Care.

patient select one of several different avatars on a computer in order to create a virtual representation of the scary voices that previously existed solely in his/her imagination. The system then synchronizes the avatar's lips with its speech, enabling a therapist to speak to the patient through the avatar in real time. The therapist encourages the patient to oppose the voice and gradually teaches them to take control of their hallucinations.

\section{Clinical care and program evaluation: General approaches and application to new technology options}

An approach to clinical and program evaluation for new technology-based health and care options may better prepare our review of the guidelines below (Table 2) [118,119]. Program evaluation has become increasingly important to meet program, patient, provider, and externally driven (Joint Commission, reimbursement) needs - and more accountability is expected by both consumers and payers. A contemporary view is that we want to do "good" care, make a difference, and self-assess rather than doing things the same old way or waiting on bad outcomes to require oversight. Contemporary program evaluation and outcome work is a substantial shift in philosophical approach for some, from seeing what happens with planned services to planning the outcomes and then designing the services-in advance. Now, it is patient- and outcome-centered, whereby the end product determines what is built or put in place - hence assessment includes satisfaction, technology, cost, clinical, process of care, and other outcomes - iterative feedback, adjustments and further study make it useful.

Parameters and methods fall into three basic frameworks that naturally overlap with one another: 1 ) research measures, in the form of feasibility, validity, reliability, satisfaction, costs and outcomes;
2) clinical care measures (e.g., mood questionnaires; habit diaries; utilization of health services); and 3) customized measures for technologies. Suggestions:

- Pick 1-2 things to measure rather than trying to measure everything (e.g., an app for substance); how frequently is the app used, frequency of near misses of or actual use of substances.

- Pick an outcome that has high heuristic value (e.g., substance relapse; averted suicide; frequency of increased visits cued by using an app).

- Adopt standardized measures already used in the literature; they typically have undergone multiple iterations, levels of review and psychometric testing.

- Use a readily available, easy to use self-report instrument or program.

- Collect data prospectively rather than retrospectively, with some exceptions.

- If possible, pick a regular evaluation interval (e.g., beginning and then 3-, 6- and 12-months).

- Follow guidelines, but assess their liabilities to anticipate problems, take corrective actions, and generalize findings among different patients.

- Identify who has the responsibility to prevent, identify, and correct the issues: patients, providers, or programs? If patient locus of responsibility is higher than before, are they ready, and what support do they need? If providers have to adjust roles and responsibilities, do it proactively, too. 


\section{Fundamental issues and components}

1. Each of the parties, picking only 1-2 foci (e.g., depression),

2. A rudimentary standard of evaluation (i.e., Patient Health Questionnaire-9; PHQ-9)?

3. A customized patient outcome (e.g., social engagement if that had lessened due to depression),

4. Satisfaction an existing 5- to 10-item survey for regular care and maybe on one technology options (e.g., a chat room or a diary for depression),

5. 1-2 parameters that "ground, tether or contextualize" the evaluation, that is,

a. Age or population (e.g., for geriatric patients over 65, ensure absence of dementia or cognitive decline; e.g.; screening for substance use like the Alcohol Use Disorders Identification Test (AUDIT))

b. Disorder-specific (e.g., plan for tracking suicidal ideation for a depressed patient, in general, or if a teenager due to high risk)

6. A log/diary by the patient and the clinician about

a. The experience, overall,

b. How and what technology was used and the relative frequency of use, too (e.g., texting 3 times/week)

Questions and considerations for patients.

7. What am I seeking when I choose to view a website, visit a chat room, get an informal suggestion or work with a clinician directly?

8. What are my means: time, $\$$, and other resources?

9. What is my learning style: alone vs. group of learners, reading versus doing something, prefer a little versus a lot of instruction?

10. Do I experience my provider the same or differently at a distance?

11. How intensive of a treatment do I want and how much should I "connect" in-person and online?

12. How do I choose a clinician based on information on the Internet, screening them by phone or in meeting them?

Clinical care issues for the provider and the patient.

13. Do the new technologies and associated behaviors affect the therapeutic relationship, clinical approach and treatment plan?

14. Is tradition care complemented by technology-based options that are patient-driven?

15. Is there a shift in action by the provider 'outside' the regular 'hour', is it paid for, how does he/she do that, and what are the unanticipated consequences?

16. Did I do things better/worse than expected, what are my technology-based strengths and did I have any unusual reactions?

17. Did the patient and I talk about the options, work together to select the plan, and how should be continue to discuss this?

Questions for clinical and program evaluation and administration.

18. Are we using a standard approach or was it left to chance or played out spontaneously?

19. What are we measuring and what is the best way to do it?

20. How often are we "checking in" done offline, is it spontaneous/cued and is it tracked, reviewed and are the important points fed back into care?

21. What are the outcomes are we measuring for patients, family, clinicians and systems?

22. Can the technology help us use resources better, as we do with interdisciplinary teams for a range of services in stepped care?

23. How does technology affect care coordination to highest clinician roles and responsibilities? For example, in addition to a regular staff/clinicians strengths/weaknesses (e.g., better inperson, worse with bipolars).

24. What additional resources (i.e., time, \$, staff/manager/medical director/administrative director, trainings) are necessary?

Table 2: An Approach to Clinical and Program Evaluation for New Technology Options and Questionnaire. 
Citation: Hilty D, Chan S, Torous J, Mahautmr J, Mucic D (2015) New Frontiers in Healthcare and Technology: Internet-and Web-Based Mental Options Emerge to Complement In-Person and Telepsychiatric Care Options. J Health Med Informat 6: 200. doi:10.4172/2157-7420.1000200

Page 8 of 14

\section{Formal guidelines for traditional TMH care, informal guidelines for new e-MH care options, and other considerations}

Introduction: Guidelines tangibly help by providing clinical criteria, protocols, algorithms, review criteria, and other components - all aimed to help clinicians make the best clinical decisions, avoid bad outcomes, and to provide an approach in uncharted circumstances. Generally, guidelines are generated when there is enough evidence to guide clinicians, such that $\mathrm{MH}$ care treatments and methods that are long running, are better reviewed. Therefore, guidelines are also on a temporal, non-linear spectrum, starting with synopsis of guidelines on eMH/TMH, texting/e-mail, social media, professionalism, and Internet-based care; person/patientcentered health information and experimental treatments are less well-developed, but have been put out due to concerns, cautions and critical incidents (Table 3 ). The ultimate judgment regarding the care of a particular patient must be made by the clinician in light of all circumstances presented by the patient and his or her family, the diagnostic and treatment options available, and available resources - and in light of all pertinent clinical, administrative and regulatory circumstances.

Traditional TMH care Guidelines: The adult ATA TMH Guideline, AACAP Practice Parameter and the Telepsychiatry Committee of AACAP form a foundation for this paper, as they cover the approach, scope, clinical, administrative and technical aspects of services for adults and children and adolescent patients [35,120]. Child and adolescent $\mathrm{MH}$ practice poses significant differences from adult practice in terms of scope of practice, the diversity of providers and the variety of specialized settings [121]. First, child and adolescent mental healthcare clinicians contend with specialized populations (e.g., developmental disorders), family and systems work, a variety of treatment modalities (e.g., parent management, play therapy) and settings (e.g., corrections/juvenile hall, school).

Internet-based videoconferencing Guidelines: The American Telemedicine Association Practice Guidelines for TMH Care [35] the more recent Practice Guidelines for Video-Based Online Mental Health Services [36] do not cover all the new nooks and crannies of technology innovations. They do not address communications between professionals and clients or patients via texting, e-mail, chatting, social network sites, online "coaching" or other non-MH services.

At the beginning of a video-based $\mathrm{MH}$ treatment with a patient (i.e., not at every subsequent encounter unless circumstances warrant re-verification), the verification of essential information is suggested because: 1) the professional needs to comply with the relevant licensing laws in his/her jurisdiction (in principle) and where the patient is located when literally receiving care (i.e., not where the patient's home is, 2) an emergency management protocol is entirely dependent upon where the patient receives services, and 3) mandatory reporting and related ethical requirements such as duty to notify are tied to the jurisdiction where the patient is receiving services. Verification includes provider name, credentials and sources to check the information on the professional (e.g., state license \#). Similarly, the name of the patient and if preferred, a government issued photo ID on the video screen or via a smart card, is suggested.

Key considerations for future guidelines on person- and patientcentered care: Clinical, legal, professional and communication ramifications of these care options will mainly be explored. Health information on the Internet for persons, patients, and caregivers is rarely regulated. It usually involves various levels of quality and synthesis, from unreviewed, unvetted submissions (e.g., anecdotes to Wikipedia to college papers to excerpts of actual research), to professionals' websites (also varying quality), to organizations/ institutions/businesses that claim some oversight/expertise, and so on. Obviously, the best quality sites in $\mathrm{MH}$ may be from the National Institute of Health or specific disorder agencies (e.g., Depression and Bipolar Support Alliance).

Regulation of psych apps is a key issue in terms of quality, in general, but also in terms of education [78]. Application stores do not routinely review of the accuracy of the content prior to publication [74], and while the majority of interns use them on a daily basis, there still needs to be more guidance and advice on this matter [75]. The Food and Drug Administration (FDA), in February 2015, noted that it considers that "many mobile apps are not medical devices" and thus do not fall under its regulatory authority. The FDA also notes that even for those apps that do meet the definition of medical devices, if they pose a low risk to the public then the FDA will consider "enforcement discretion" and may not enforce requirements. Thus at this time the mobile $\mathrm{MH}$ space for apps is largely unregulated by the FDA [122]. On the other hand, regulations can stifle the development of innovative apps that are not connected to a life-sustaining medical device (i.e., outright fatal errors are rare). And, after all, patient educational materials and books in the United States are not subject to regulation, either.

New digital communication from one user to another user using standard protocols: e-mail, SMS text messaging, multiple messaging service (MMS) messaging, and instant messaging have issues that appear to be similar for proprietary networks (e.g., Twitter direct messages, Facebook Messenger, Epic My Chart electronic medical record messaging, My HealtheVet electronic medical record messaging).

Requests for other contact between visits (e.g., texts, e-mails) are increasing due to time online [123]. Asynchronous written or e-mail language is good for answering yes/no questions, trading a piece of information (e.g., confirming appointment, medication side effect), but it is not synchronous. Emails 'should' be sent during regular working hours to attend to expectation and boundary issues [123]. Asynchronous methods do not afford vocal nuances like pitch modulations, changing volume, and meaningful pauses, and there is no accompanying body language; this may lead to misinterpretations and have unexpected consequences. (Interestingly, some of this, too, may be "in play" soon, if patients and doctors begin to send audio- or video-clip messages!)

Guidelines on use of social media: Preliminary guidelines discuss concerns about patient privacy, professional image, confidentiality, and defined expectations for use in general $[124,125]$ and for social media [126]. Providers should consider the professional and ethical responsibilities for routes of communication, absences, or any other changes in accessibility in advance. Guidelines for social media use also suggest discussions with the patient in advance, as part of the informed consent process:

- Consider pros/cons of gathering information about patients: intent, use and implications

- Physician-produced blogs, microblogs, and comments: "pause before posting" and "step back" to consider what is conveyed to the public about the physician and the profession 
General

1. Maintain professionalism at all times — follow institutional policies, "assume that all information exchanged is public and posted in a medium no different than a newspaper," and maintain a disclaimer.

2. Be authentic, have fun, and do not be afraid - "the only way to create meaningful relationships over social media is to be genuine."

3. Ask for help - pay attention to "how people interact (e.g., etiquette)" and "mimic the social media service and community's practices (so long as they are professional)."

Traditional TMH care guidelines

4. The adult ATA TMH Guideline (ATA 2009; Yellowlees et al 2010).

5. AACAP Practice Parameter and the Telepsychiatry Committee of AACAP (AACAP 2008) and steps toward a formal guideline (Hilty et al 2015).

Key considerations for website health information, texting and e-mail

6. Health information on the Internet for persons, patients, and caregivers is rarely regulated. When possible, seek out information from organizations/ institutions/businesses that have some oversight/expertise (e.g., the National Institutes of Health; specific disorder agencies like the Depression and Bipolar Support Alliance).

7. Be cautious, due to unclear privacy/confidentiality issues, about use of new digital communication from one user to another user using standard protocols (i.e., e-mail, SMS text messaging, multiple messaging service (MMS) messaging, and instant messaging. The issues appear to be similar for proprietary networks (e.g., Twitter direct messages, Facebook Messenger, Epic MyChart electronic medical record messaging, My HealtheVet electronic medical record messaging).

8. Requests for other contact between visits (e.g., texts, e-mails) with asynchronous modalities is good for some things (e.g., answering yes/no questions, trading a piece of information) but not other things (i.e., emergencies, complex decisions). Attend to expectation, boundary and nuances in communication of one mode versus another.

9. Use e-mail, text, instant messaging only for patients who maintain in-person follow-up.

\section{Social media}

10. Be mindful of privacy, professional image, confidentiality, and expectations for use in general (Recupero et al 2005; Frankish et al 2012) and for social media (Koh et al 2013); follow institutional policies.

11. Consider pros/cons of gathering information about patients: intent, use and implications

12. Physician-produced blogs, microblogs, and comments: "pause before posting" and "step back" to consider what is conveyed to the public about the physician and the profession

Professionalism beyond social media

13. Contextualize decision-making in terms of professionalism and follow the lead of organizations have specifically made recommendations about professionalism and social media (e.g., The American College of Physicians, Canadian Medical Association, and British Medical Association (Farnan et al 2013; AMA 2011).

14. Separate personal and professional life (Behnke 2008; CMA 2015), if it can be done (BMA 2013; Grajales et al 2014).

15. Contextualize approaches based on education/training/supervisory issues (DeJong et al 2012).

Internet-based videoconferencing guidelines

16. The American Telemedicine Association Practice Guidelines for Video-Based Online Mental Health Services cover teleMH (TMH) services (ATA 2013).

17. Follow state (e.g., licensing laws), federal, and other regional

18. Verify provider and patient information.

VR guidelines (Yellowlees et al 2012)

19. All patients should undergo an in-person or telemedicine assessment to evaluate patient safety and appropriateness for treatment with this modality, establish care, confirm their 
diagnosis, create a treatment plan and discuss consent. This is particularly important in a potential emergency situation where therapists have to know the physical location of a patient, as per telemedicine guidelines, in order to call for help.

20. All patients should then sign a written consent form if required in the state in which they reside (which can be done electronically), be trained in how to use the virtual environment, be given a tour, and receive a copy of their diagnostic assessment and treatment plan.

21. If patients and providers are federal employees, they can be treated in the virtual environment from any state by any provider. If the patient or the provider is not a federal employee, the treating provider must be licensed to practice in the state from which the patient logs in.

22. All providers will have fully authenticated avatars using their real names, and will have biographies published that link their professional identities to their avatars for patients to read.

23. Patients and providers will then schedule sessions for either counseling or cognitive behavioral therapy, or a combination of both.

24. Any major changes to the treatment plan, such as altered medications, should require an inperson telemedicine consultation.

25. Either the provider or patient may at any time either cease therapy, or request a telemedicine or in-person consultation to review progress.

Table 3: Synopsis of Guidelines on Emh, Person/Patient-Centered Health Information, Texting/E-Mail, Social Media, Professionalism, Internet-Based Care, and Experimental Treatments.

- Digital venues for communicating with colleagues about patient care: ensure security/privacy and follow policies of institution

Professionalism guidelines (including, but beyond social media): The effect on professionalism and education/training of the next generations has been explored [127]. Many organizations have specifically made recommendations about professionalism and social media (e.g., The American College of Physicians, Canadian Medical Association, and British Medical Association [128,129], focusing on communication with patients, gathering information, online education and other topics. Separation of personal and professional life is suggested [130-132]. In fact, a physician should assume that one's private profile can be found. The Journal of Medical Internet Research provided guidelines based on a review of over 100 articles, websites, policies and reports [133]:

- Maintain professionalism at all times - follow institutional policies, "assume that all information exchanged is public and posted in a medium no different than a newspaper," and maintain a disclaimer.

- Be authentic, have fun, and do not be afraid - "the only way to create meaningful relationships over social media is to be genuine."

- Ask for help - pay attention to "how people interact (e.g., etiquette)" and "mimic the social media service and community's practices (so long as they are professional)."

- Attend to privacy/confidentiality, and clinical boundaries; separate personal and professional sites [134].

VR guidelines [114]: Patients only receiving generic educational information on an open virtual reality environment can be anonymous, but providers within that world should be fully identified, as should be their corresponding avatars. For patients who wish to move to a secure virtual reality environment for some form of virtual therapy, whether this is individual counseling or cognitive behavioral therapy, the provider should treat the patient in accordance with the following protocols to ensure high practice standards, and legal and ethical processes:
- All patients should undergo an in-person or telemedicine assessment to evaluate patient safety and appropriateness for treatment with this modality, establish care, confirm their diagnosis, create a treatment plan and discuss consent. This is particularly important in a potential emergency situation where therapists have to know the physical location of a patient, as per telemedicine guidelines, in order to call for help.

- All patients should then sign a written consent form if required in the state in which they reside (which can be done electronically), be trained in how to use the virtual environment, and receive a copy of their diagnostic assessment and treatment plan.

- HIPAA compliance of the virtual environment must be documented, verifiable and ensured prior to patient contact.

- If patients and providers are federal employees, patients can be treated from a provider from any state. If the patient or the provider is not a federal employee, the treating provider must be licensed to practice in the state from which the patient logs in.

- All providers will have fully authenticated avatars using their real names, and will have biographies published that link their professional identities to their avatars for patients to read.

- Patients and providers will then schedule sessions for either counseling or cognitive behavioral therapy, or a combination of both.

- Any major changes to the treatment plan, such as altered medications, should require an in-person telemedicine consultation.

- Either the provider or patient may at any time either cease therapy, or request a telemedicine or in-person consultation to review progress.

\section{Discussion}

Web- and Internet-based resources are remarkably popular with the public, patients and providers - this is a new era of medicine. Technology is frequently used, is readily accessible and satisfies users. 
Citation: Hilty D, Chan S, Torous J, Mahautmr J, Mucic D (2015) New Frontiers in Healthcare and Technology: Internet-and Web-Based Mental Options Emerge to Complement In-Person and Telepsychiatric Care Options. J Health Med Informat 6: 200. doi:10.4172/2157-7420.1000200

Page 11 of 14

It facilitates openness to engage with others and begin self-assessment and care; its ability to help people change behaviors and engage additional clinical services appears modest, though this is inadequately evaluated. For persons or patients not in care, use of health issues for common, non-acute problems appears to work, though a one-time clinical evaluation may help them better place options in context. Formal treatments over the Internet, asynchronous care models, or traditional video-based services are as good as or better than in-person services, though an incomplete range of services has been evaluated. Healthcare systems use technology to disseminate treatments to many points-of-service, in-time, which helps to customize care. More research is needed on the application of new technologies to clinical care, particularly treatment interventions, and also head-to-head studies (e.g., in-person versus eMH care; e-MH option one versus option two). Finally, if eMH option one is combined with in-person or $\mathrm{TMH}$ care, are outcomes improved in an additive versus multiplicative fashion?

The proposed framework of low intensity/informal/health information to high intensity/formal health/standardized treatments may help participants "step back" and gain perspective on trends. Such a framework had not existed in the literature, though it is parallel to stepped, integrated, and other models of service delivery. Traditional care, depending on the setting, may have little to very formal, robust evaluation. While guidelines help to provide perspective and broad themes for doing things well, practice parameters and minimal standards may also be useful as technology-based options continue to emerge. At a minimum, though, since the options are less standardized, it is best to pro-actively evaluate care more thoroughly, in order to identify positives and liabilities and then move to discuss reasonable outcomes, reflect on expectations, and prevent/minimize problems.

Clinicians have to become aware of, adapt to, and clinically oversee some or all of these new technology options in order to provide the best care - this means adding to or upgrading all parts of clinical care (e.g., review of decision-making, new advisory roles to patients, greater complexity of care, hybrid models of care). This also impacts standards for professionalism, privacy/confidentiality, tracking of data, evaluation and general practice management. Most of these technologies - not just social media, texting and e-mail - impact these areas. Patients are empowered by increased access to information, providers and exposures - in ways that can be adjusted to patient needs and comfort, with or without clinician supervision [135]. Their attitudes toward clinicians and MH care may shift, for the better or for the worse (e.g., they may want to do more out of the clinic, expect more availability via technology, or like technology-savvy providers). It is critical that clinicians increase their awareness and understanding of web-based options to understand patients' concerns, changes in the therapeutic relationship, and potential positive/negative effects on outcomes. Clinicians need to create a positive climate, discuss options with patients, and help them to incorporate user-friendly approaches.

Technology may soon reshape healthcare service delivery - a particularly interesting area will be the shift from clinic- or doctorcentered care to person- or patient-centered care. Mobile health, the patient centered medical home and stepped care models are already moving that direction. Another fascinating area is the use, research, and outcomes related to hybrid models of care [37,107]. Combining traditional in-person approaches with online services - or combining two technology interventions. MH providers may soon practice inperson, virtually, or both, but how they spend their time may change (e.g., $1 / 2$ traditional, $1 / 4$ review of tech results, and $1 / 4$ interdisciplinary team leadership). Clinicians, clinical managers and administrators need to shift their philosophy-from seeing what happens-to designing the services in advance to achieve outcomes. The scope/foci of evaluation, potential levels of depth/complexity, and duration of measurement (i.e., short- to long-term) require thoughtful planning [118]. A key question is, "If the person or patient is in care, should this be overseen by a professional, and if so, how?" Legal, reimbursement and other factors need to be re-evaluated.

\section{Conclusions}

Web- and Internet-based resources are remarkably popular with the public, patients and providers - this is a new era of medicine. Patients are empowered by increased access to information, providers and exposures - in ways that can be adjusted to patient needs and comfort, with or without clinician supervision. These steps help patients initiate, participate and steer their care. Clinicians have to become aware of, adapt, use sound clinical judgment, and serve new advisory roles to patients, as we are all challenged to keep the best of $\mathrm{MH}$ care, yet make it more accessible. Prioritization of outcomes and evaluation in the provision of clinical (TMH) services is important not just after you start, but preferably before all parties start something new, though that is seldom the case.

\section{Acknowledgments}

1. American Telemedicine Association, Telemental Health Interest Group

2. Department of Psychiatry \& Behavioral Sciences, Keck School of Medicine at USC

3. UC Davis Department of Psychiatry \& Behavioral Sciences

4. Harvard Medical School and Department of Psychiatry

5. Keck Medical Center at USC TeleCARETM

\section{References}

1. Internet World Stats (2011) Internet users in the world-Distribution by world regions.

2. Internet World Stats. United States of America: Internet usage and broadband usage report, 2011. February 28, 2015.

3. Ferreira-Lay P, Miller S (2008) The quality of Internet information on depression for lay people. Psychiatric Bulletin 32: 170-173.

4. Kalk NJ, Pothier DD (2008) Patient information on schizophrenia on the Internet. Psychiatric Bulletin 32: 409-411.

5. Nemoto K, Tachikawa H, Sodeyama N, Endo G, Hashimoto K, et al. (2007) Quality of Internet information referring to mental health and mental disorders in Japan. Psychiatry Clin Neurosci 61: 243-248.

6. Morahan-Martin JM (2004) How internet users find, evaluate, and use online health information: a cross-cultural review. Cyberpsychol Behav 7: 497-510.

7. Andersson G, Bergström J, Carlbring P, Lindefors N (2005) The use of the Internet in the treatment of anxiety disorders. Curr Opin Psychiatry 18: 73-77.

8. Erwin BA, Turk CL, Heimberg RG, Fresco DM, Hantula DA (2004) The Internet: home to a severe population of individuals with social anxiety disorder? J Anxiety Disord 18: 629-646.

9. Murray E, Lo B, Pollack L, Donelan K, Catania J, et al. (2003) The impact of health information on the internet on the physician-patient relationship: patient perceptions. Arch Intern Med 163: 1727-1734.

10. Boyd DM, Ellison NB (2007) Social network sites: Definition, history, and scholarship. J Comput-Mediated Commun 13: 210-230.

11. Laranjo L, Arguel A, Neves AL, Gallagher AM, Kaplan R, et al. (2015) The influence of social networking sites on health behavior change: a systematic review and meta-analysis. J Am Med Inform Assoc 22: 243-256.

12. Hu C, Kung S, Rummans TA, Clark MM, Lapid MI (2015) Reducing caregiver stress with internet-based interventions: a systematic review of open-label and randomized controlled trials. J Am Med Inform Assoc 22: e194-209. 
Citation: Hilty D, Chan S, Torous J, Mahautmr J, Mucic D (2015) New Frontiers in Healthcare and Technology: Internet-and Web-Based Mental Options Emerge to Complement In-Person and Telepsychiatric Care Options. J Health Med Informat 6: 200. doi:10.4172/2157-7420.1000200

Page 12 of 14

13. Lal S, Adair CE (2014) E-mental health: a rapid review of the literature. Psychiatr Serv 65: 24-32

14. Christensen H, Griffiths K, Evans K (2002) E-Mental Health in Australia: Implications of the Internet and Related Technologies for Policy. Canberra, Commonwealth Department of Health and Ageing.

15. Lambousis E, Politis A, Markidis M, Christodoulou GN (2002) Development and use of online mental health services in Greece. J Telemed Telecare 8 Suppl 2: 51-52.

16. Ybarra ML, Eaton WW (2005) Internet-based mental health interventions. Ment Health Serv Res $7:$ 75-87.

17. Hilty DM, Ferrer DC, Parish MB, Johnston B, Callahan EJ, et al. (2013) The effectiveness of telemental health: a 2013 review. Telemed J E Health 19: $444-454$

18. Yellowlees PM, Odor A, losif AM, Parish MB, Nafiz N, et al. (2013) Transcultura psychiatry made simple-asynchronous telepsychiatry as an approach to providing culturally relevant care. Telemed J E Health 19: 259-264.

19. deBronkart $D$ (2015) From patient centred to people powered: autonomy on the rise. BMJ 350: h148.

20. Miles A, Mezzich J (2011) The care of the patient and the soul of the clinic: Person-centered medicine as an emergent model of modern clinical practice. Int J Pers Centered Med 1: 207-222.

21. Ekman I, Swedberg K, Taft C, Lindseth A, Norberg A, et al. (2011) Personcentered care-ready for prime time. Eur J Cardiovasc Nurs 10: 248-251.

22. Hilty DM, Yellowlees PM, Chan S, Parish MB. Telepsychiatry: Effective evidence-based and at a tipping point in healthcare delivery. Psych Clin N Amer.

23. Hilty DM, Snowdy CE, Shoemaker EZ, Hilty YSG, Carli V: Social media and clinical practice: Why it is popular, tips/guidelines on how to work with patients, and dealing with pathological Internet use. Med Res Arch.

24. Celio AA, Winzelberg AJ, Wilfley DE, Eppstein-Herald D, Springer EA, et al (2000) Reducing risk factors for eating disorders: comparison of an Internetand a classroom-delivered psychoeducational program. J Consult Clin Psychol 68: 650-657.

25. Ritterband LM, Thorndike F (2006) Internet interventions or patient education web sites? J Med Internet Res 8: e18.

26. Christensen H, Griffiths K, Groves C, Korten A (2006) Free range users and one hit wonders: community users of an Internet-based cognitive behaviour therapy program. Aust N Z J Psychiatry 40: 59-62.

27. Clarke G, Eubanks D, Reid E, Kelleher C, O'Connor E, et al. (2005) Overcoming Depression on the Internet (ODIN) (2): a randomized trial of a self-help depression skills program with reminders. J Med Internet Res 7: e16.

28. Andersson G, Carlbring P, Holmstrom A, Sparthan E, Furmark T, et al. (2006) Internet-based self-help with therapist feedback and in vivo group exposure for social phobia: a randomized controlled trial. J Consult Clin Psychol 74 677-686.

29. Ljotsson B, Lundin C, Mitsell K, Carlbring P, Ramklint M, et al. (2007) Remote treatment of bulimia nervosa and binge eating disorder: a randomized trial of Internet-assisted cognitive behavioural therapy. Behav Res Ther 45: 649-661.

30. Mucic D, Hilty DM, Parrish MB, Yellowlees PM. Web- and Internet-based services: education, support, self-care and formal treatment approaches. In Key Issues in e-Mental Health (Eds) Mucic D, Hilty DM, Springer Publishing.

31. Powell J, Clarke A (2006) Internet information-seeking in mental health: population survey. Br J Psychiatry 189: 273-277.

32. Montagni I, Parizot I, Horgan A, Gonzalez-Caballero JL, Almenara-Barrios J, et al. (2014) Spanish students' use of the Internet for mental health information and support seeking. Health Informatics $\mathrm{J}$

33. Ben-Zeev D (2014) How I stopped fearing technology-based interventions. Psychiatr Serv 65: 1183

34. Chan SR, Torous JB, Hinton WL, Yellowlees PM. Psychiatric apps: Patient self-assessment, communication, and potential treatment interventions. In: Key Issues in e-Mental Health. Eds Mucic D, Hilty DM, Springer Publishing.

35. Yellowlees P, Shore J, Roberts L; American Telemedicine Association (2010) Practice guidelines for videoconferencing-based telemental health - Octobe 2009. Telemed J E Health 16: 1074-1089.
36. American Telemedicine Association (2013) American Telemedicine Association Practice Guidelines for Video-Based Online Mental Health Services.

37. Yellowlees P, Nafiz N (2010) The psychiatrist-patient relationship of the future anytime, anywhere? Harv Rev Psychiatry 18: 96-102.

38. Institute of Medicine (IOM) (2011) Clinical Practice Guidelines We Can Trust.

39. AHRQ Clinical Guidelines and Recommendations (2015).

40. Cochrane Community Database of Systematic Reviews (CDSR) (2015)

41. Ransohoff DF, Pignone M, Sox HC (2013) How to decide whether a clinical practice guideline is trustworthy. JAMA 309: 139-140.

42. Kauer SD, Mangan C, Sanci L (2014) Do online mental health services improve help-seeking for young people? A systematic review. J Med Internet Res 16 e66.

43. Berger M, Wagner TH, Baker LC (2005) Internet use and stigmatized illness. Soc Sci Med 61: 1821-1827.

44. Griffiths KM, Calear AL, Banfield M (2009) Systematic review on Internet Support Groups (ISGs) and depression: What is known about depression ISGs? J Med Internet Res 11: e41.

45. Griffiths KM, Calear AL, Banfield M (2009) Systematic review on Internet Support Groups (ISGs) and depression (1): Do ISGs reduce depressive symptoms? J Med Internet Res 11: e40.

46. Shore JH, Aldag M, McVeigh FL, Hoover RL, Ciulla R, et al. (2014) Review of mobile health technology for military mental health. Mil Med 179: 865-878.

47. Schrank B, Sibitz I, Unger A, Amering M (2010) How patients with schizophrenia use the internet: qualitative study. J Med Internet Res 12: e70.

48. Koivunen M, Välimäki M, Pitkänen A, Kuosmanen L (2007) A preliminary usability evaluation of Web-based portal application for patients with schizophrenia. J Psychiatr Ment Health Nurs 14: 462-469.

49. Ahmed M (2002) Computer-facilitated dialogue with patients who have schizophrenia. Psychiatr Serv 53: 99-100.

50. Yellowlees PM, Cook JN (2006) Education about hallucinations using an internet virtual reality system: a qualitative survey. Acad Psychiatry 30: 534 539.

51. Siemer CP, Fogel J, Van Voorhees BW (2011) Telemental health and webbased applications in children and adolescents. Child Adolesc Psychiatr Clin N Am 20: 135-153.

52. Younes N, Chollet A, Menard E, Melchior M (2015) E-mental health care among young adults and help-seeking behaviors: a transversal study in a community sample. J Med Internet Res 17: e123.

53. Antze $P$ (2010) On the pragmatics of empathy in the neurodiversity movement In: Ordinary Ethics (Eds) Lambek M. Fordham University Press, New York NY, 310-327.

54. Gowen K, Deschaine M, Gruttadara D, Markey D (2012) Young adults with mental health conditions and social networking websites: seeking tools to build community. Psychiatr Rehabil J 35: 245-250.

55. Mittal VA, Tessner KD, Walker EF (2007) Elevated social Internet use and schizotypal personality disorder in adolescents. Schizophr Res 94: 50-57.

56. Lewandowski J, Rosenberg BD, Jordan Parks M, Siegel JT (2011) The effect of informal social support: Face-to-face versus computer-mediated communication. Comput Hum Behav 27: 1806-1814.

57. Ben-Zeev D, Corrigan PW, Britt TW, Langford L (2012) Stigma of mental illness and service use in the military. J Ment Health 21: 264-273.

58. Pietrzak RH, Johnson DC, Goldstein MB, Malley JC, Southwick SM (2009) Perceived stigma and barriers to mental health care utilization among OEF-OIF veterans. Psychiatr Serv 60: 1118-1122.

59. Wilson JA, Onorati K, Mishkind M, Reger MA, Gahm GA (2008) Soldier attitudes about technology-based approaches to mental health care. Cyberpsychol Behav 11: 767-769.

60. Blusi M, Dalin R, Jong M (2014) The benefits of e-health support for older family caregivers in rural areas. J Telemed Telecare 20: 63-69.

61. Chi NC, Demiris G (2015) A systematic review of telehealth tools and interventions to support family caregivers. J Telemed Telecare 21: 37-44. 
Citation: Hilty D, Chan S, Torous J, Mahautmr J, Mucic D (2015) New Frontiers in Healthcare and Technology: Internet-and Web-Based Mental Options Emerge to Complement In-Person and Telepsychiatric Care Options. J Health Med Informat 6: 200. doi:10.4172/2157-7420.1000200

Page 13 of 14

62. Styra R (2004) The Internet's impact on the practice of psychiatry. Can J Psychiatry 49: 5-11.

63. Luxton DD, Hansen RN, Stanfill K (2014) Mobile app self-care versus in-office care for stress reduction: a cost minimization analysis. J Telemed Telecare 20: $431-435$.

64. Collins FS, Varmus $\mathrm{H}$ (2015) A new initiative on precision medicine. N Engl J Med 372: 793-795.

65. Torous J, Chan RS, Yee-Marie Tan S, Behrens J, Matthew I, et al. (2014) Patient smartphone ownership and interest in mobile apps to monitor symptoms of mental health conditions: A survey in four geographically distinct psychiatric clinics. JMIR Ment Health 1: e5.

66. Ben-Zeev D, Davis KE, Kaiser S, Krzsos I, Drake RE (2013) Mobile technologies among people with serious mental illness: opportunities for future services. Adm Policy Ment Health 40: 340-343.

67. Campbell B, Caine K, Connelly K, Doub T, Bragg A (2015) Cell phone ownership and use among mental health outpatients in the USA. Pers Ubiquitous Comput 19: $367-378$

68. Harrison V, Proudfoot J, Wee PP, Parker G, Pavlovic DH, et al. (2011) Mobile mental health: review of the emerging field and proof of concept study. J Ment Health 20: 509-524.

69. Chan S, Torous J, Hinton L, Yellowlees P (2014) Mobile tele-mental health increasing applications and a move to hybrid models of care. Healthcare 2 220-233.

70. Moskowitz DS, Young SN (2006) Ecological momentary assessment: what it is and why it is a method of the future in clinical psychopharmacology. J Psychiatry Neurosci 31: 13-20.

71. Torous J, Staples $P$, Shanahan M, Lin C, Peck P, et al. (2015) Utilizing a custom application on personal smartphones to assess phq-9 depressive symptoms in patients with major depressive disorder. JMIR Ment Health 2: e8.

72. Shaw SC, Marks IM, Toole S (1999) Lessons from pilot tests of computer selfhelp for agora/claustrophobia and panic. MD Comput 16: 44-48.

73. Kenwright M, Liness S, Marks I (2001) Reducing demands on clinicians by offering computer-aided self-help for phobia/panic. Feasibility study. $\mathrm{Br}$ Psychiatry 179: 456-459.

74. Barton AJ (2012) The regulation of mobile health applications. BMC Med 10: 46.

75. O'Connor P, Byrne D, Butt M, Offiah G, Lydon S, et al. (2014) Interns and their smartphones: use for clinical practice. Postgrad Med J 90: 75-79.

76. Subhi Y, Todsen T, Ringsted C, Konge L (2014) Designing web-apps for smartphones can be easy as making slideshow presentations. BMC Res Notes 7: 94 .

77. Katzman J, Abbass A, Coughlin P, Arora S (2015) Building connections through teletechnologies to augment resident training in psychodynamic psychotherapy. Acad Psychiatry 39: 110-113.

78. Zhang MW, Ho CS, Ho RC (2014) Methodology of development and students' perceptions of a psychiatry educational smartphone application. Technol Health Care 22: 847-855.

79. American Psychiatric Association (2000) Diagnostic and Statistical Manual, Fourth Edition, Text Revision. American Psychiatric Publishing, Incorporated, Washington, DC

80. Moreno MA, Jelenchick LA, Egan KG, Cox E, Young H, et al. (2011) Feeling bad on Facebook: depression disclosures by college students on a social networking site. Depress Anxiety 28: 447-455

81. Riper H, Kramer J, Smit F, Conijn B, Schippers G, et al. (2008) Web-based self-help for problem drinkers: a pragmatic randomized trial. Addiction 103 : 218-227.

82. Luxton DD, McCann RA, Bush NE, Mishkind MC, Reger GM (2011) mHealth for mental health: Integrating smartphone technology in behavioral healthcare. Prof Psychol Res Practice 42: 505-512.

83. Kroenke K, Spitzer RL, Williams JB (2001) The PHQ-9: validity of a brief depression severity measure. J Gen Intern Med 16: 606-613.
84. Bush NE, Skopp N, Smolenski D, Crumpton R, Fairall J (2013) Behavioral screening measures delivered with a smartphone app: psychometric properties and user preference. J Nerv Ment Dis 201: 991-995.

85. National Center for Telehealth and Technology (2015) PTSD Coach (Internet). PTSD Coach | t2health, 2013.

86. Agyapong VI, Rogers C, Machale S, Cotter D (2010) Factors predicting adherence with psychiatric follow-up appointments for patients assessed by the liaison psychiatric team in the emergency department. Int J Psychiatry Med 40: $217-228$

87. Gonzalez J, Williams JW Jr, Noël PH, Lee S (2005) Adherence to mental health treatment in a primary care clinic. J Am Board Fam Pract 18: 87-96.

88. Zanjani F, Davis T, Newsham P, Kruger TM, Munk N, et al. (2015) Management of psychiatric appointments by telephone. J Telemed Telecare 21: 61-63.

89. Kunigiri G, Gajebasia N, Sallah D (2014) Improving attendance in psychiatric outpatient clinics by using reminders. J Telemed Telecare 20: 464-467.

90. Andersson G, Hedman E (2013) Effectiveness of guided Internet-based cognitive behavior therapy in regular clinical settings. Verhaltenstherapie 23 140-148.

91. Andersson G, Hesser $H$, Veilord A, Svedling L, Andersson F, et al. (2013) Randomised controlled non-inferiority trial with 3-year follow-up of internetdelivered versus face-to-face group cognitive behavioural therapy for depression. J Affect Disord 151: 986-994.

92. Ruwaard J, Lange A, Schrieken B, Dolan CV, Emmelkamp P (2012) The effectiveness of online cognitive behavioral treatment in routine clinical practice. PLoS One 7: e40089.

93. Kok G, Bockting C, Berger H, Smit F, Riper H (2014) Mobile cognitive therapy: Adherence and acceptability of an online intervention in remitted recurrently depressed patients. Internet Interventions 1: 65-73.

94. Amstadter AB, Broman-Fulks J, Zinzow H, Ruggiero KJ, Cercone J (2009) Internet-based interventions for traumatic stress-related mental health problems: a review and suggestion for future research. Clin Psychol Rev 29: 410-420.

95. Carlbring P, Ekselius L, Andersson G (2003) Treatment of panic disorder via the Internet: a randomized trial of CBT vs. applied relaxation. J Behav Ther Exp Psychiatry 34: 129-140.

96. Carlbring P, Nordgren LB, Furmark T, Andersson G (2009) Long-term outcome of Internet-delivered cognitive-behavioural therapy for social phobia: a 30-month follow-up. Behav Res Ther 47: 848-850.

97. Kiropoulos LA, Klein B, Austin DW, Gilson K, Pier C, et al. (2008) Is internetbased CBT for panic disorder and agoraphobia as effective as face-to-face CBT? J Anxiety Disord 22: 1273-1284.

98. Odor A, Yellowlees P, Hilty D, Parish MB, Nafiz N, et al. (2011) PsychVACS: a system for asynchronous telepsychiatry. Telemed J E Health 17: 299-303.

99. Butler TN, Yellowlees P (2012) Cost analysis of store-and-forward telepsychiatry as a consultation model for primary care. Telemed J E Health 18: 74-77.

100. Hilty DM, Yellowlees PM, Cobb HC, Bourgeois JA, Neufeld JD, et al. (2006) Models of telepsychiatric consultation--liaison service to rural primary care. Psychosomatics 47: 152-157.

101. Hilty DM, Marks SL, Urness D, Yellowlees PM, Nesbitt TS (2004) Clinical and educational telepsychiatry applications: a review. Can J Psychiatry 49: 12-23.

102. Hilty DM, Ingraham RL, Yang SP, Anders TF (2004) Multispecialty telephone and e-mail consultation for patients with developmental disabilities in rural California. Telemed J E Health 10: 413-421.

103. Neufeld JD, Yellowlees PM, Hilty DM, Cobb H, Bourgeois JA (2007) The e-Mental Health Consultation Service: providing enhanced primary-care mental health services through telemedicine. Psychosomatics 48: 135-141.

104. Yellowlees PM, Hilty DM, Marks SL, Neufeld J, Bourgeois JA (2008) A retrospective analysis of a child and adolescent eMental Health program. J Am Acad Child Adolesc Psychiatry 47: 103-107.

105. Richardson L, McCauley E, Katon W (2009) Collaborative care for adolescent depression: a pilot study. Gen Hosp Psychiatry 31: 36-45. 
Citation: Hilty D, Chan S, Torous J, Mahautmr J, Mucic D (2015) New Frontiers in Healthcare and Technology: Internet-and Web-Based Mental Options Emerge to Complement In-Person and Telepsychiatric Care Options. J Health Med Informat 6: 200. doi:10.4172/2157-7420.1000200

Page 14 of 14

106. Fortney JC, Pyne JM, Mouden SP, Mittal D, Hudson TJ, et al. (2013) Practicebased versus telemedicine-based collaborative care for depression in rura federally qualified health centers: a pragmatic randomized comparative effectiveness trial. Amer J Psychiatry 170: 414-425

107. Myers KM, Vander Stoep A, Zhou C, McCarty CA, Katon W (2015) Effectiveness of a telehealth service delivery model for treating attention-deficit hyperactivity disorder: results of a community-based randomized controlled trial. J Amer Asso Child Adol Psych Apr 54: 263-274.

108. Todder D, Kaplan Z (2007) Rapid eye movements for acute stress disorder using video conference communication. Telemed J E Health 13: 461-463.

109. Wakeling M, Heaney D (2011) Competitive health services in sparsely populated areas - eHealth applications across the urban-rural dimension. Report on Scotland pilots.

110. Krämer NC (2008) Nonverbal communication. In: Human Behavior in Military Contexts, (Eds) Blascovich J, Hartel CR. The National Academies Press, Washington, DC: 150-188.

111. Kim J (2011) Two routes leading to conformity intention in computer-mediated groups: matching versus mismatching virtual representations. J Comput Mediat Commun 16: 271-287.

112. Fabri M, Moore DJ, Elzouki SYA(2007) Emotionally expressive avatars for chatting, learning and therapeutic intervention. In: Human-Computer Interaction. $\mathrm{HCl}$ Intelligent Multimodal Interaction Environments Lecture Notes in Computer Science. Ed. Jacko JA. Springer Publishing, Berlin, Germany: 275-285.

113. Cheng Y, Ye J (2010) Exploring the social competence of students with autism spectrum conditions in a collaborative virtual learning environment - the pilot study. Comput Educ 54: 1068-1077.

114. Yellowlees PM, Holloway KM, Parish MB (2012) Therapy in virtua environments--clinical and ethical issues. Telemed J E Health 18: 558-564.

115. Georgescu AL, Kuzmanovic B, Roth D, Bente G, Vogeley K (2014) The use of virtual characters to assess and train non-verbal communication in highfunctioning autism. Front Hum Neurosci 8: 807

116. Parks P, Cruz R, Ahn SJ (2014) Don't hurt my avatar: The use and potentia of digital self- representation in risk communication. Int $\mathrm{J}$ Robots Educ Art 4: 11-20.

117. Leff J, Williams G, Huckvale M, Arbuthnot M, Leff AP (2014) Avatar therapy for persecutory auditory hallucinations: What is it and how does it work? Psychosis 6: 166-176.

118. Hilty DM, Yellowlees PM, Nasatir SEH, Shoemaker EZ, Johnston B, et al. (2014) Program Evaluation and Practical: Supporting Pragmatic Data-Driven Clinical Videoconferencing CV Services. Behavioral Telehealth Series Volume 1- Clinical Video Conferencing: Program Development and Practice. Springer Press, New York, NY: 105-134
119. Hilty DM, Yellowlees PM, Myers KM, Rabinowitz T. The effectiveness of telemental health: Evidence base, how to choose the model based ease/cost/ strength, and future approaches to research. In Key Issues in e-Mental Health. (Eds) Mucic D, Hilty DM, Springer Publishing.

120. AACAP Practice Parameter on Telepsychiatry with Children and Adolescents (2008).

121. Hilty DM, Shoemaker EZ, Myers KM, Snowdy C, Yager J. Issues and steps toward a clinical guideline for telemental health for care of children and adolescents. J Child Adol Psychopharm.

122. Food and Drug Administration (FDA) (2015).

123. Hilty DM, Belitsky R, Cohen MB, Cabaniss DL, Dickstein LJ, et al. (2015) Impact of the information age on residency training: communication, access to public information, and clinical care. Acad Psychiatry 39: 104-107.

124. Recupero PR (2005) E-mail and the psychiatrist-patient relationship. J Am Acad Psychiatry Law 33: 465-475.

125. Frankish K, Ryan C, Harris A (2012) Psychiatry and online social media potential, pitfalls and ethical guidelines for psychiatrists and trainees. Australas Psychiatry 20: 181-187.

126. Koh S, Cattell GM, Cochran DM, Krasner A, Langheim FJ, et al. (2013) Psychiatrists' use of electronic communication and social media and a proposed framework for future guidelines. J Psychiatr Pract 19: 254-263.

127.DeJong SM, Benjamin S, Anzia JM, John N, Boland RJ, et al. (2012) Professionalism and the internet in psychiatry: what to teach and how to teach it. Acad Psychiatry 36: 356-362.

128. Farnan JM, Snyder Sulmasy L, Worster BK, Chaudhry HG, Rhyne JA, et al 2013) Online medical professionalism: patient and public relationships: policy statement from the American College of Physicians and the Federation of State Medical Boards. Ann Intern Med 158: 620-627.

129. American Medical Association (2011) Opinion 9.124-Professionalism in the Use of Social Media. AMA Code of Medical Ethics.

130. Behnke S (2008) Ethics in the age of the Internet. Monitor Psychology 39: 74

131. Canadian Medical Association (2015) Social media and Canadian physicians - issues and rules of engagement.

132. British Medical Association (2013) Using social media: practical and ethica guidance for doctors and medical students.

133. Grajales FJ 3rd, Sheps S, Ho K, Novak-Lauscher H, Eysenbach G (2014) Social media: a review and tutorial of applications in medicine and health care. J Med Internet Res 16: e13.

134.Bishop M, Yellowlees P, Gates C, Silberman G (2011) Facebook goes to the doctor. In: ACM Press 978-1-4503-1082-6/11/12 13-20.

135. Sturmberg JP, O'Halloran D, Colagiuri R, Fernandez A, Lukersmith S, et al (2014) Health care frames - from Virchow to Obama and beyond: the changing frames in health care and their implications for patient care. J Eval Clin Pract 20: $1036-1044$ 